\title{
EL MODERNISMO HISPANOAMERICANO Y EL TEATRO: UNA REFLEXION
}

\author{
P O R
GUILLERMO SCHMIDHUBER \\ University of Circinnati
}

En los últimos tres lustros del siglo $\mathrm{xx}$, cuando se está celebrando el primer centenario de la iniciación del modernismo hispanoamericano, es conveniente hacer un análisis del teatro coetáneo a este movimiento literario. El corpus crítico dedicado al modernismo es mayúsculo para la poesía y la narrativa, no así para el teatro, que inclusive no alcanza el epíteto de modernista, a pesar de que varios escritores pertenecientes a este movimiento escribieron dramas, como José Martí y Enrique Larreta, así como sus contemporáneos Amado Nervo, Manuel José Othón, Roberto J. Payró y Federico Gamboa. La pregunta crucial de esta reflexión es: ¿Existió un teatro nutrido por el sentir y el estilo del quehacer literario modernista, o sólo compartió el tiempo y el espacio con el nacimiento de 1a literatura hispanoamericana «a la universalidad del arte»? ${ }^{1}$ Esta pregunta es la razón de esta reflexión.

Es conveniente indagar el pasado inmediato del teatro que precedía al año de 1888, que marca, al menos en el tiempo, el inicio del modernismo americano con la publicación de $A z u l$, de Rubén Darío. El romanticismo, que en la poesía se había ido diluyendo, seguía imperante en el teatro. El genio de José Zorrilla era aún central en el teatro peninsular -muere en 1897-, con las presencias vivas de Echegaray — gana su Nobel en 1905y de Tamayo y Baus. El teatro mundial arrastraba también el romanticismo por ser aún gustado por la butaquería; no hay que olvidar que uno de los mayores triunfos escénicos que recuerda Francia es el estreno de Cyrano de Bergerac, de Edmond Rostand, en París (1897), e inmediatamente en Madrid; al año siguiente, la compañía de María Guerrero lleva esta

${ }^{1}$ Alfredo A. Roggiano, «Filiación cultural del modernismo hispanoamericano», en la revista Mundi, Córdoba, Argentina, núm. 1 (1986), p. 29. 
obra en gira triunfal por América. Durante ese período luchaban simultáneamente por el predominio escénico el realismo naturalista de Émile Zola y de Dumas, el romanticismo lírico de Gabriel D'Annunzio, que triunfaba en los escenarios de Italia y Francia, y el drama social del nórdico Henrik Ibsen. El siglo moribundo anunciaba cautelosamente el advenimiento de un nuevo teatro: el que habría de imperar en el siglo xx, con el estreno de $U b u R o i$, de Jarry (1886), y con los primeros dramas de August Strindberg. El simbolismo poético también invadía la escena, y el teatro de Maeterlinck era quizás el más gustado por los grupos intelectuales del París del nuevo siglo. Todos estos nombres y algunas de las obras cruzaban el Atlántico con la misma rapidez que los versos de Mallarmé, Verlaine y Baudelaire.

La dramaturgia hispanoamericana seguía de cerca el barullo del devenir del teatro europeo. Los gustos románticos eran también bienvenidos; en México se prolongó la dramaturgia romántica zorrillesca hasta finales del siglo xIx con José Peón y Contreras (1843-1907), hasta el punto que el crítico Carlos González Peña afirma que este dramaturgo «llegó tarde, cuando ya el drama romántico que pretendió revivir tocaba a su ocaso o había pasado de tono" ${ }^{2}$. Junto a este romanticismo vespertino nacía el teatro de interés social, como el escrito por el cubano José Armas y Cárdenas, con Los triunfadores (1895), obra naturalista que «sufre de las debilidades casi innatas del teatro social del siglo xIx: manejo forzado de la trama, exageración del personaje, en especial del portavoz del autor» ${ }^{3}$. En México, los Gamboa, Federico y José Joaquín, escribieron un teatro similar: del primero descuella La venganza de la gleba, que es el primer intento de un drama rural en su país. Los nombres de dramaturgos coetáneos al modernismo son numerosos, pero pocos dejan huella. Frank Dauster resume el teatro del final del siglo xIx y de los albores del siglo xx en estas palabras:

Las tablas están dominadas por una mezcla no muy feliz del género chico, realismo frecuentemente de carácter social, y el romanticismo trasnochado estilo Echegaray ${ }^{4}$.

${ }^{2}$ Carlos González Peña, Historia de la literatura mexicana (México: Editorial Cultura y Polis, 1940), p. 259. Véase también: Julio Jiménez Rueda, Letras mexicanas en el siglo XIX (México: Fondo de Cultura Económica, 1944); Francisco Monterde, Teatro mexicano del siglo XX (México: Fondo de Cultura Económica, 1956), vol. I, y Rodolfo Usigli, México en el teatro (México: Imprenta Mundial, 1932).

${ }^{3}$ Frank N. Dauster, Historia del teatro hispanoamericano (México: Ediciones Andrea, 1973), p. 18 .

${ }^{4}$ Dauster, p. 25. 
Se podría reflexionar sobre la ausencia de dramaturgos de la talla de un Darío y sobre las exigencias que el devenir histórico demandaba sobre el teatro durante el advenimiento del modernismo hispanoamericano.

E1 modernismo es, sobre todo, «un cambio que hace época... una nueva instrumentación» ${ }^{5}$; «un renacimiento, una dinámica de porvenir» ${ }^{6}$; un \iempo en que «el escritor hispanoamericano se sintió por primera vez influyente en el mundo cultural de su lengua» ${ }^{7}$, "con el confinamiento de las literaturas comarcanas» ${ }^{8}$. Por desgracia, el teatro no experimenta este milagro en el cambio de siglo; ecos encontramos de nuevas búsquedas, tales como la utilización de la luz y del sonido tecnificados, y, sobre todo, la incorporación de otra perspectiva del teatro, ya no como arte de placer, sino como testimonio de una sociedad.

El genio dramático del teatro américo-hispano de este período es FLoRENCIO SÁNCHEZ (1875-1910); escribe un teatro realista, con influencias del naturalismo francés, sobre la problemática de la sociedad rioplatense, siempre bajo la óptica de Ibsen: el criollaje y la dignidad, la crisis del gaucho al intentar convertirse en citadino, en obras como $M$ 'hijo el dotor, La gringa y Barranca abajo. En tanto Florencio Sánchez triunfa como dramaturgo, hay un fracaso del modernismo en cuanto al teatro, ya que aunque los tipes son de psicología y lenguaje americanos, la forma dramática constituye una prueba de que hasta los albores del siglo $\mathrm{xx}$ las corrientes europeas continuaron dominando en el teatro hispanoamericano. Lo lugareño del lenguaje y de la trama sólo contribuye a hacer de estas obras expresiones comarqueñas, sin que puedan ser ejemplos del retorno de los galeones modernistas, para usar la conocida expresión de Max Henríquez Ureña sobre la contribución de la literatura de Hispanoamérica al viejo continente.

\section{El teatro de MARTí o AMOR CON AMOR NO BASTA}

El teatro de José Martí (1853-1895) ha sido poco estudiado, ya que su presencia de héroe, poeta y narrador sobrepasan con mucho a su exigua

${ }^{5}$ José María Valverde, Historia de la literatura universal (Barcelona: Planeta, 1974), p. 144. Del mismo, La literatura de Hispanoamérica (Barcelona: Planeta, 1977).

"Alfredo A. Roggiano, «Filiación cultural del modernismo hispanoamericano», loc. cit., p. 30.

${ }^{1}$ Raúl Silva Castro, Antología crítica del modernismo hispanoamericano (New York: Las Américas Publishing Co., 1963), p. 33.

${ }^{8}$ Saúl Yurkievich, Celebración del modernismo (Argentina: Tusquets editores), p. 7. 
producción teatral. Mas, sin embargo, es iluminador analizar el estilo de sus obras de teatro en comparación con el pendular de los estilos dramáticos en el cambio de siglo. Abdala, su primera incursión teatral, se publica en 1869 en la revista La patria libre; para ella la escribe cuando su autor tiene solamente dieciséis años. Es un drama de libertad, escrito en endecasílabos zorrillescos, con un solo acto de ocho escenas; la trama trata de la muerte del caudillo morisco Abdala en la sublevación de Alpujarras en 1571, en la Sierra Nevada de Granada, último refugio de los moros. El parangón es obvio: los moros del siglo xvi y los cubanos del siglo xrx luchan contra el imperialismo español:

AbDala: Pues decid al tirano que en la Nubia (¿Cuba?)

Hay un héroe por veinte de sus lanzas:

Que del aire se atreva a hacerse dueño:

Que el fuego a los hogares hace falta:

Que la tierra la compre con su sangre:

Que el agua ha de mezclarse con sus lágrimas ${ }^{9}$.

La acción dramática apunta a sostener más de un acto escénico, pero Martí precipita el final con la muerte prematura del héroe, como tantas veces lo hicieron fallidamente los dramaturgos románticos. Las últimas palabras de Abdala, antes de morir en brazos de su madre, son premonitorias de la muerte del mismo Martí:

EsPERTA: ¿Que no llore me dices? ¿Y tu vida

Alguna vez me pagará la patria?

AB̉DALA: ¡La vida de los nobles, madre mía,

Es luchar y morir por acatarla,

Y si es preciso, con su propio acero,

Rasgarse, por salvarla, las entrañas!

Mas... me siento morir: es mi agonía.

¡Nubia venció! Muero feliz: la muerte

Poco me importa, pues logré salvarla...

$\lceil\mathrm{Oh}$, qué dulce es morir cuando se muere

Luchando audaz por defender la patria!

(Cae en brazos de los guerreros) ${ }^{10}$.

La segunda vez que Martí escribe un drama es en Madrid, en 1872, Adúltera por título, la primera versión terminada en febrero de 1874 y la

9 José Martí, Teatro (Cuba: Editorial Letras Cubanas, Centro de Estudios Martianos, 1981), p. 35 («Prólogo», de Rine Leal).

${ }^{10}$ Martí, op. cit., p. 47. 
segunda, inconclusa, sin fecha, ambas publicadas póstumamente. Martí nos dice:

A los dieciocho años estuve, por vanidad de la edad, abocado a una grave culpa. Lo rojo brilla y seduce, y vi unos labios muy rojos en la sombra; pero interiormente iluminado por el misterioso concepto del deber, llevé la luz a la tiniebla, y vi de cerca todos sus errores... ${ }^{11}$

La trama narra un adulterio, cuyo triángulo no se asemeja al teatro de Echegaray, sino que anuncia el simbolismo, movimiento literario que se estaba fraguando entonces y que exigía que toda obra trascendiera los límites de lo puramente material, para expresar los estados del ser, reflejando lo mágico y lo misterioso del universo. Los cuatro personajes de Adúltera son estereotipos, casi entelequias: Grossermann (hombre-alto, el marido), Gutterman (hombre-bueno, el amigo), Possermann (hombre-vil, el amante) y además una mujer, Fleisch (carne, la esposa). Aunque la acción sucede en el siglo XVII, todo señala al siglo XIX, en el que el joven Martí, de diecinueve años, recordaba una aventura adúltera, utilizando un teatro cerebral, de largos monólogos, y con entradas de personajes que abren y cierran puertas al antojo del incipiente dramaturgo. Sin embargo, el diálogo es inusitado en lengua castellana, el poeta modernista parece asomarse por momentos para esconderse en un rigor de lenguaje como no ha vuelto a cantar el diálogo poético en el teatro hispanoamericano:

Grossermann (a la adúltera): Tú lo dijiste... Tú, que decías que me amabas, tuviste tiempo para pensar en que yo tenía años. - Tengo yo canas. -Cuarenta veces en mi vida he visto cómo los árboles - com. padecidos en el invierno de la tierra- le envían para protegerla del hielo sus hojas secas y marchitas: —cuarenta veces he visto tornarse a la primavera las hojas caídas en flores hermosísimas, porque eran hijas del agradecimiento y de la luz: —cuarenta veces ha abrumado mi frente el peso sombrío de la melancólica atmósfera del otoño: ¿pero entiendes tú un espíritu tan potente que anime con su fuego las entrañas heladas del invierno, que rompa por encima de toda pesadumbre, que doble con su peso el cuerpo que lo aprisiona y que lo encierra? - iEse es mi espíritu! — ¡El cuerpo cada día se me hunde: el alma, más libre cada día, es por instantes más enérgica y alta! -iLa nieve de mis canas no es la ceniza que deja el fuego al morix, - es la capa blanca que rodea al hierro ardiente y encendido, encendido en dolor, en to que no muere, en Dios, en ti! - Eres bella; yo no te amaría si la belleza no fuese lo menos hermoso de ti, - si las flores perdurables de tu alma

${ }^{11}$ Martí, op. cit., p. 11. 
- porque, aunque no me ames, ¿tú serás pura? - ¿verdad, luz mía, que tú serás siempre pura?... ${ }^{12}$

El mismo Martí nos define su drama con estas palabras: «Es un drama apasionado y extraño en la forma, real en la esencia y en la observaciớn de sus caracteres. La expresión rinde culto a la belleza, a la sencillez, a la sobriedad y a la verdad» ${ }^{13}$. Sus definiciones de extraño en la forma y real en la esencia son dos elementos que muy poco aparecerán, por desgracia, en el teatro hispano posterior.

El teatro martiano tiene su contribución al género chico con Amor con amor se paga (1875), representado con extraordinario éxito en el teatro Principal de México por la compañía española de Enrique Gutasp de Peris. Es un juguete cómico para actor y actriz, en octosílabos jocundos. La trama es simple, la actriz pide al autor una obra que, improvisada en un juego lleno de simpatía, llega a convertirse en la obra representada al público, con los personajes de Leonor y Julián. El lenguaje vivo recuerda al Martí de otras lides:

Ex: ¡Nada es azul en la vida,
Oh mortal, de lo que ves,
Si no miras al través
De una mujer bien querida!
Nada, ioh mortal!, es el hombre
Que sin mujer va en la tierra,
Y sin el hijo que encierra
Orgullo y germen de un nombre.
iLeonor, mi amada Leonor,
Cómo más presto me hablaras,
Si en el alma me miraras
El lago azul de tu amor! ${ }^{14}$

Mas en esta obra también está presente un mal crónico del teatro hispanoamericano de este período: el menosprecio de la creación dramática por el propio autor, quien parece excusarse de la precipitación de la escritura y la exigua revisión. Al final de la pieza el personaje autor envía una carta al público, que la actriz lee, en donde expresa sus intenciones como creador:

\section{ElLA: Juguete es éste sencillo \\ Hecho al correr de la pluma \\ en un instante de suma}

\footnotetext{
12 Martí, op. cit., p. 90.

${ }^{13}$ Martí, op. cit., p. 11.

${ }^{14}$ Martí, op. cit., p. 161.
} 
Pereza. E1 alma sin brillo

Está de quien lo escribió:

Cuando sin patria se vive,

Ni luz del sol se recibe,

Mi vida el alma gozó.

Vino Guasp: quiso tener

Piececilla baladí,

Por darte, público, a ti

Algo agradable que ver.

Quien sin patria en que vivir,

$\mathrm{Ni}$ mujer por quien morir,

Ni soberbia que tentar,

Sufre, y vacila, y se halaga

Imaginando que al menos

Entre los públicos buenos

Amor con amor se paga ${ }^{15}$.

Este «correr de la pluma en un instante de suma pereza», con «el alma sin brillo», será un mal endémico, como veremos más adelante, hasta la epifanía de los teatros nacionales, en los años treinta, en los que sí hay una volición permanente y una concienzuda labor de los dramaturgos.

La última obra dramática de Martí es Patria y libertad -Drama indio-, escrito en Guatemala y mencionado en su testamento literario. Cuando hace memoria de su riqueza literaria desperdigada recuerda el «borrador dramático que en unos cinco días me hizo escribir el gobierno sobre la independencia guatemalteca ${ }^{16}$, que permanecía inédito en manos de un amigo. Martí muere el mismo año y su última obra es publicada póstumamente. El drama es heroico, en dos actos cortos, pero queda inconcluso el último, del que se guarda un apunte. El verso es nuevamente enđecasílabo y de tono romántico; Zorrilla y su propia Abdala parecen repetirse:

Martino: ¡Libres, libres como el quetzal! iLibertad santa!

Patria libre... Coana... esposa mía...

la inmensa procesión que se levanta, marca la feliz ruta del futuro.

Ya veo el porvenir que se agiganta.

Ya veo el porvenir amplio y seguro.

Hombres libres serán los descendientes de tu amor y del mío ${ }^{17}$.

\footnotetext{
${ }^{15}$ Martí, op. cit., p. 164.

${ }_{16}$ Martí, op. cit., p. 165.

${ }^{17}$ Martí, op. cit., p. 189.
} 
Es de notar un texto de Martí que apareció póstumamente en sus papeles:

Hay dos teatros: el social, que requiere un arte menor, local y relativo, y el de arte mayor, el teatro de arquetipos. Como hay dos vidas, la que se arrastra y la que se desea ${ }^{18}$.

Panorama que vislumbra las dos vertientes del teatro que habrían de venir, y que Martí no escribió. Por tanto, el que pudo ser el dramaturgo más dotado del modernismo, no es recordado como tal; y muchas historias de la literatura, que le dan amplia cabida como poeta, prosista y héroe americano, olvidan sus acercamientos al género dramático como autor y como excelente crítico ${ }^{19}$.

\section{TEATro sin DESTino MANIFIESTO}

E1 destino del teatro durante el modernismo es precario: Nervo escribió el libreto de una zarzuela - Consuelo- y algunos diálogos que llamó Teatro mínimo; Manuel José Othón escribe varios dramas bajo la influencia de Echegaray, a pesar de que su poesía respondía a los tiempos en que vivía. El mejor drama de Othón es El último capítulo, pieza en un acto en la que Cervantes es llevado a escena para que ahí escriba el último capítulo del Quijote en el año 1615. Dauster afirma que Othón «remedaba a Echegaray en obras que sufren el abuso melodramático y convencionalismo de carácter» ${ }^{20}$. Por el contrario, Roberto J. PAYró (1867-1928) escribe ocho obras de teatro que se adelantan a sus tiempos al llevar al meollo del conflicto dramático la reconciliación entre el sector rural y el progreso técnico, en Sobre las ruinas (1904), y la injusta rigidez de la justicia, en su quizás mejor obra, Marcos Severi (1905). Sus obras no alcan-

${ }^{18}$ Martí, op. cit., p. 193.

${ }^{19}$ La importancia de Martí como crítico y cronista teatral es más trascendente que sus labores dramatúrgicas. Sus múltiples artículos publicados en España, Estados Unidos e Hispanoamérica constituyen uno de los mayores corpus crítico del teatro coetáneo al modernismo. Su interés abarcó numerosos autores: Molière, Racine, Corneille, Zola, Feuillet, destacan entre los artículos dedicados al teatro francés; Calderón, Echegaray, Peón Contreras, Ruiz de Alarcón, la Avellaneda, Manuel Gorostiza y muchos otros autores hispanos pasan por su escrutinio crítico. Es memorable el artículo sobre Sarah Bernhardt. Véase Rine Leal, «Prólogo», en José Martí, Teatro (Cuba: Editorial Letras Cubanas, 1981), pp. 7-30. En este libro se encuentra una selección de sus mejores artículos, véase la sección «Críticas y Crónicas», pp. 233-431.

${ }^{20}$ Frank N. Dauster, op. cit., p. 15. 
zan una gran calidad dramática, pero son las mejores salidas de pluma de escritores coetáneos del modernismo.

La relación del teatro español y el hispanoamericano era grande a fines del siglo XIX, y esto puede palparse con la rapidez que el teatro benaventino y el de los hermanos Alvarez Quintero cruzaba el Atlántico, con gran éxito de público e influencia en los dramaturgos hispanoamericanos. Benavente estrena su primera obra en 1894, El nido ajeno, y en pocas temporadas se convierte en el dramaturgo más importante de España. Dos de sus mejores obras se estrenan en España y en América en la primera década del siglo: Los malhechores del bien (1905) y Los intereses creados (1907). La primera obra de Serafín y Joaquín Alvarez Quintero fue Esgrima y amor (1888), y desde ese año invaden el teatro de habla hispánica con sus obras, logrando grandes éxitos de público, hasta el punto que cuando Benavente hace su primer viaje a América en 1906, percibe la predilección del público bonaerense por el teatro andaluz de los Quintero, quizás porque «El patio, Las flores, El genio alegre pudieran parecer obras de costumbres argentinas», en explicación de Benavente ${ }^{21}$. Bajo el influjo de este teatro, que resultaba revolucionario dentro de la tradición romántica trasnochada, se escribieron muchas obras, en un cierto despertar de siglo americano. Quizá las mejores sean las de Gregorio De LAFERRÈre (18671913), quien triunfa en los escenarios de Buenos Aires en la época de Florencio Sánchez con su teatro costumbrista, especialmente en Las de Barranco (1908), que alcanzó un gran éxito y fue traducida por Santiago Rusiñol al catalán y estrenada en Barcelona en 1911.

Es ejemplificador el motivo de Laferrère para escribir teatro, pues nos pinta su falta de vocación como dramaturgo. E1 mismo confiesa:

He escrito para el teatro como he hecho muchas otras cosas raras en mi vida: por el deseo de conocer algo que no conocía, de experimentar emociones nuevas, por no aburrirme lo mismo que el día anterior... Pero nunca he tomado en serio mi papel de hombre de teatro ${ }^{22}$.

Qué gran diferencia con la volición de ser poeta de Darío o Martí, y con sus búsquedas desasosegadas de una nueva estética.

Una de las primeras novelas hispanoamericanas de triunfo en España fue La gloria de don Ramiro —Una vida en tiempos de Felipe II- (1908),

${ }^{21}$ Jacinto Benavente, El teatro del pueblo (Madrid, 1909), pp. 126-127. Consúltese Francisco Ruiz Ramón, Historia del teatro español (Madrid: Ediciones Cátedra, vol. I, 1971; vol. II, 1975).

${ }^{22}$ Gregorio de Laferrère, Obras escogidas (Buenos Aires: Angel Estrada, 1943), p. 263. Consúltese Raúl Héctor Castagnino, Literatura dramática argentina: 17171967 (Buenos Aires: Editorial Pleamar, 1968). 
de Enrioue Larreta (1883-1961), que es sin duda una obra cumbre de la novela modernista. El teatro de Larreta no es tan conocido: La lampe d'argile, escrita en francés en 1912, bajo la influencia de Gabriel D'Annunzio, es una obra posromántica; Lo que buscaba don Juan (1923), sobre el donjuanismo, es una pieza en verso que apunta a lo que pudo haber sido el teatro modernista si se hubiera escrito en su momento. Mas, sin embargo, la obra más interesante de Larreta, verdadera joya del modernismo, es En la tela del sueño, que debió haber sido escrita en los albores del siglo $\mathrm{xx}, \mathrm{y}$ no tardíamente, como se hizo, en 1950, cuando Larreta tenía setenta y siete años. En la historia del teatro hispanoamericano esta obra no tiene cabida, es una pieza anacrónica que señala el camino que debió haber recorrido el teatro hispanoamericano en los primeros años de nuestro siglo para que el milagro del modernismo pudiera haber influido al teatro. El diálogo está escrito en prosa, pertenece al teatro simbolista con reminiscencias del último Ibsen. Las acotaciones adquieren una importancia no conocida antes en el teatro hispanoamericano, bordeando, por un lado, la novelística y, por el otro, los niveles mágicos del sueño:

La hora del crepúsculo. El sol acaba de ocultarse detrás de las negras montañas, y sólo algunas nubes inflamadas doran con su resplandor suavemente los árboles y se reflejan profundas en el agua inmóvil del lago. Anselmo endereza con paso vacilante hacia un ribazo de la orilla. De pronto, al llegar al borde, se detiene, mira hacia lo alto y se arroja. Sonia, que llega en ese momento, lanza agudas voces pidiendo socorro. Acuden dos hombres en un bote y sacan a Anselmo, casi ahogado y con el cuerpo endurecido por el frío del agua ${ }^{23}$.

Estas ambiciosas acotaciones recuerdan a las de Valle Inclán. El teatro hispanoamericano encontró demasiado tarde el camino que le hubiera conducido en el devenir de los tiempos al teatro simbolista y al surrealista, y de ahí al teatro del absurdo, sin que estos movimientos fueran de nuevo modas europeas importadas, sino formando parte sustancial del proceso histórico del teatro hispanoparlante de América.

\section{REFLEXIÓN}

Definitivamente, no existió un teatro modernista dentro del movimiento de este nombre en Hispanoamérica. Los dramaturgos y el público deci-

${ }^{23}$ Enrique Larreta, Obras completas (Madrid: Editorial Plenitud, 1951), p. 1380. Véase Arturo Berenguer Carisomo, Los valores eternos en la obra de Enrique Larreta (Buenos Aires: Sopena Argentina, 1946). 
dieron en aquellos años mirar al pasado y llevar a la escena el longevo romanticismo y el fácil costumbrismo. Solamente Florencio Sánchez ${ }^{24}$ ha pasado a ser una figura permanente en la historia del teatro hispanoamericano coetáneo al modernismo. La narrativa y la poesía modernista fueron el detonador que abrió hace un siglo las letras américo-hispanas al mundo; el teatro se quedó a la zaga y solamente encontró su rumbo en la generación del 24, con Rodolfo Usigli, Samuel Eichelbaum y Robert Arlt, y otros más que forjaron teatros nacionales - icomarqueños?-, sobre los que se fundamentó lo que hoy llamamos el teatro hispanoamericano.

El modernismo fue una oportunidad y un riesgo: la poesía y la narrativa los vislumbraron y apostaron para ganar; el teatro no vivió ese riesgo al vibrar en demasía con los movimientos del teatro europeo, sin encontrar el camino avistado por Martí de un teatro extraño en la forma y real en la esencia. Aún hoy vibra el teatro hispanoamericano intensamente con las corrientes teatrales europeas - Brecht, Artaud, Ionesco-, sin que haya encontrado un camino propio comparable al que la literatura de la América española ha alcanzado, con tan excepcionales niveles de madurez, que la han convertido en eje de la literatura mundial.

\footnotetext{
${ }^{24}$ Florencio Sánchez, Teatro (Buenos Aires: Sopena Argentina, 1961).
} 
